\title{
Transfer of a Plasmid between Streptomyces Species
}

\author{
By D. A. HOPWOOD AND HELEN M. WRIGHT \\ John Innes Institute, Colney Lane, Norwich, NOR $70 \mathrm{~F}$
}

(Received 5 March I973)

\begin{abstract}
SUMMARY
It has been shown previously that IF strains of Streptomyces coelicolor harbour a plasmid, SCP I, lacking in UF strains, and that IF strains inhibit aerial mycelium production of UF strains. In the present study, IF strains of $S$. coelicolor, but not UF strains, were found to inhibit I 9 out of 32 wild-type streptomycetes belonging to various species. Some of these presumptive UF wild-types were grown in mixed culture with IF strains of $\mathrm{A} 3(2)$ and it was found, by a simple visual procedure, that SCP I was transferred to one of them, converting it to an IF strain. The rates of loss of SCP I from this strain, both spontaneously and after u.v. irradiation, were found to be similar to those from IF strains of $\mathrm{A}_{3}(2)$. The plasmid had no detectable effect on recombination within the new strain.
\end{abstract}

\section{INTRODUCTION}

The wild-type strain A3(2) of Streptomyces coelicolor has been shown to harbour a plasmid called SCP I (Vivian, I97I) which determines its fertility characteristics; these have been designated IF (Initial Fertility). The plasmid is lost by derivatives of $\mathrm{A} 3$ (2) (IF) to give UF (Ultra-fertility) strains with a spontaneous frequency of about 0.03 to $0.3 \%$, which is increased to I to $2 \%$ by u.v. or X irradiation (Vivian \& Hopwood, 1970). The plasmid may rarely become spontaneously associated in a stable manner with the chromosome to give strains of the NF (Normal Fertility) type, which act as donors of chromosome fragments to IF or UF recipients (Hopwood, Harold, Vivian \& Ferguson, I969; Vivian \& Hopwood, I970), and is also transiently associated with the chromosome in unstable donors of other types, which may owe their donor characteristics to their possession of substituted SCP I plasmids analogous to those in F prime strains of Escherichia coli (Hopwood, Chater, Dowding \& Vivian, I973; Vivian \& Hopwood, I973).

SCP 1 is responsible, when it interacts with the chromosome, for high levels of transfer of chromosomal material between derivatives of $\mathrm{A} 3(2)$. The frequency of recombinants amongst the spores of mixed cultures of NF and UF strains reaches $100 \%$ (Hopwood et al. 1969) and is in the region of $10 \%$ and $\mathrm{I} \%$ in $\mathrm{NF} \times \mathrm{IF}$ and $\mathrm{NF} \times \mathrm{NF}$ mixtures respectively. In IF $\times \mathrm{UF}$ mixtures the frequency of transfer of SCP I from IF to UF is very high (Vivian, I97I), but the frequency of gene transfer is low; it varies widely with different strain combinations, in the range $\mathrm{IO}^{-5}$ to $\mathrm{IO}^{-3}$ with respect to the minority parent (Hopwood et al. 1973). However, gene transfer takes place in the absence of SCP I, the frequency of recombinants in UF $\times$ UF mixtures usually being at the lower end of the range of frequencies found in IF $\times$ UF mixtures (Vivian \& Hopwood, 1970; Hopwood et al. 1973). Moreover, the characteristic of recombination in Streptomyces coelicolor, that large groups of linked markers are transferred together, indicating a conjugation type of process, is found also in UF $\times$ UF mixtures (Hopwood et al. I973).

Apart from its effects on fertility, only two other phenotypic effects of SCP I have so far 
been recognized in strains harbouring it, whether autonomously in IF strains (Vivian, I97I) or interacting with the chromosome in NF (Hopwood, 1972) or other donor strains (Vivian \& Hopwood, 1973); it causes the excretion of a diffusible substance which inhibits aerial mycelium production by UF strains, and confers resistance to this substance.

The present paper describes the discovery that several different wild-type strains belonging to the genus Streptomyces can be diagnosed as equivalent to UF strains of Streptomyces coelicolor A3(2). Attempts to infect them with SCP I from A3(2) have so far been successful in one case.

\section{METHODS}

General. Complete (CM) and minimal (MM) media and standard cultural and genetic techniques with Streptomyces coelicolor were those described by Hopwood (I967). Nutrient broth and agar for production and assay of phage VP 5 were described by Dowding (1973).

Strains. The mutant and recombinant derivatives of $\mathrm{A} 3(2)$ were from our stock culture collection. Strain I 326 was 'strain 66' referred to by Lomovskaya, Mkrtumian, Gostimskaya \& Danilenko (1972) and kindly supplied by Dr N. D. Lomovskaya, Institute of Genetics and Selection of Industrial Micro-organisms, Moscow. Six Streptomyces albus strains were kindly supplied by Dr J. Lacey, Rothamsted Experimental Station, Harpenden, and the $S$. virginiae strain by Dr M. Mergeay, C.E.N., Mol, Belgium. Other strains were from a collection of streptomycetes assembled in this laboratory for reasons unrelated to genetic studies.

Ultraviolet irradiation (u.v.). This was done by the method of Harold \& Hopwood (1970).

Testing of fertility by 'plate crossing'. This was done by a modification of the indirect selection procedure of Sermonti \& Casciano (1963) as described by Hopwood et al. (I969) and Vivian \& Hopwood (1970).

Phage techniques. The phage was a clear-plaque mutant of the temperate phage VP 5 (Dowding \& Hopwood, 1973). Lysates were prepared by the confluent-plate method (Dowding, 1973).

\section{RESULTS}

\section{Testing of other wild-types for presence or absence of SCP $\mathrm{I}$}

If an unrelated strain harboured a plasmid resembling SCP I it would be expected specifically to inhibit aerial mycelium production of a UF derivative of Streptomyces coelicolor A3(2) but not of an IF derivative. Conversely, strains lacking SCP I might be inhibited by an IF derivative of A3(2) but not by a UF derivative. Two series of tests were performed. In one, a spore suspension of an IF strain (I04: hisAI uraAI strAI) was spread on one set of plates of CM and a suspension of a UF strain (I I90: hisAI uraAI strAI) on another set. Loopsful of spores of each streptomycete to be tested were placed in areas about $\mathrm{I} \cdot 5 \mathrm{~cm}$ diam. on one plate of each set. Four tests were performed on each plate. After incubation for 2 to 4 days the plates were examined for inhibition by the tested strains of growth and/or aerial mycelium production of strain II90 but not of IO4, indicating the tested strain to be 'IF-like'. In the other series of tests, each strain to be studied was spread on a plate of CM and patches of 104 and I 190 were placed on it. After incubation as before, significant interactions were those in which 104, but not I190, inhibited the tested strain, indicating it to be 'UF-like'.

The first series of tests yielded no clear If-like reaction on the part of the tested strains. Several streptomycetes inhibited A3(2) derivatives, but the IF and UF derivatives were equally affected, indicating a cause, such as antibiotic production, unrelated to a plasmid of the SCP I type. On the other hand, several streptomycetes were identified as UF-like by the second 
Table I. Identification of UF-like streptomycetes

\begin{tabular}{|c|c|c|c|c|c|c|c|}
\hline \multicolumn{3}{|c|}{ Strain } & \multicolumn{5}{|c|}{ Strain } \\
\hline $\begin{array}{c}\text { Stock } \\
\text { no. }\end{array}$ & Description & Origin $\dagger$ & $\begin{array}{l}\text { UF- } \\
\text { likeł }\end{array}$ & $\begin{array}{c}\text { Stock } \\
\text { no. }\end{array}$ & Description & Origin $\dagger$ & $\begin{array}{l}\text { UF- } \\
\text { liket }\end{array}$ \\
\hline I 201 & S. acrimycini & IPVI 610 & - & 1153 & S. coelicolor* & Bradley 199 & + \\
\hline I 160 & S. albus & CMI 52766 & + & 1206 & S. echinatus & CUB95 & - \\
\hline 1202 & S. albus & ATCC 6 I 8 & + & I 203 & S. glaucescens & ETH24204 & \pm \\
\hline 1770 & S. albus & Lacey A75 & + & 1472 & S. glaucescens & ETH22794 & - \\
\hline 1771 & S. albus & Lacey A I 38 & + & 1210 & S. griseovirticillatus & CUB532 & - \\
\hline 1772 & S. albus & Lacey AI94 & + & I I6I & S. griseus & ATCCIOI 37 & - \\
\hline I 774 & S. albus & Lacey A505 & + & 1326 & S. lividans & Lomovskaya 66 & + \\
\hline 1775 & S. albus & Lacey A647 & + & 1459 & S. rimosus & NRRL2234 & - \\
\hline 1776 & S. albus & Lacey A I063 & + & 1274 & S. venezualae & NCIB823I & - \\
\hline 1087 & S. coelicolor* & Kutzner 673 & + & 1777 & S. virginiae & M. Mergeay & + \\
\hline I I 50 & S. coelicolor* & Floodgate 204 & + & I 176 & S. viridochromogenes & Lechevalier 93 & - \\
\hline 1152 & S. coelicolor* & Sermonti iss & + & & & & \\
\hline
\end{tabular}

* Resemble $S$. violaceoruber according to Kutzner \& Waksman (I959).

$\uparrow \mathrm{IPV}=$ Istituto Patologia Vegetale, Milan; CUB $=$ University of Bradford.

\$ Inhibited by 104 but not by II.90.

series of tests (Table I); in addition to the named strains in Table I, four out of nine unidentified streptomyces reacted as UF-like.

There are several limitations of these tests. For example, a potentially interesting plasmid in a new strain could fail to cause it to produce a diffusible substance resembling that evoked by SCP I, so that the UF tester strain would not be inhibited; or SCP I could fail to confer resistance to an analogous but chemically different substance evoked by a new plasmid, so that UF and IF testers would be inhibited to the same extent by the new strain. Conversely a new UF-like strain might have chromosomal, rather than plasmid-borne resistance to the SCP I substance, and so would not be"revealed as UF-like in the test; or a new plasmid might fail to confer resistance to the SCP I substance, so that a strain might appear UF-like while still harbouring a plasmid. Nevertheless, the tests revealed a number of presumptive UF strains, some of which were used as possible recipients of SCP I from IF derivatives of A3(2).

\section{Attempts to transfer SCP I from A3(2) to other streptomycetes}

Nine streptomycetes were chosen that reacted as UF-like in the tests just described and grew well on unsupplemented MM. These were strains I I 53, I I60, I 202, I 326 and I 777 (Table I) and $1158,1159,1195$ and 1458 (unidentified). A culture of each of these strains was mixed with IF strain I04 of Streptomyces coelicolor A3(2) on slants of CM, and after 4 days of incubation spore suspensions were prepared from the mixtures, serially diluted tenfold and spread on plates of unsupplemented MM, selecting against strain 104. A parallel series of platings was made in which a loopful of a dense spore suspension of the same Uf-like streptomycete that had been included in the mixed culture was spread on the plates with the spore suspension from the cross. The rationale for this procedure, which was first tested with mixtures of known IF and UF derivatives of $\mathrm{A3}$ (2), was as follows. If a fraction of the prototrophic plating units from the mixed culture had been converted to IF by acquisition of SCP I, then they should show themselves as small colonies surrounded by a zone of inhibition of the unconverted UF-like strain on the second series of platings. The first series of 


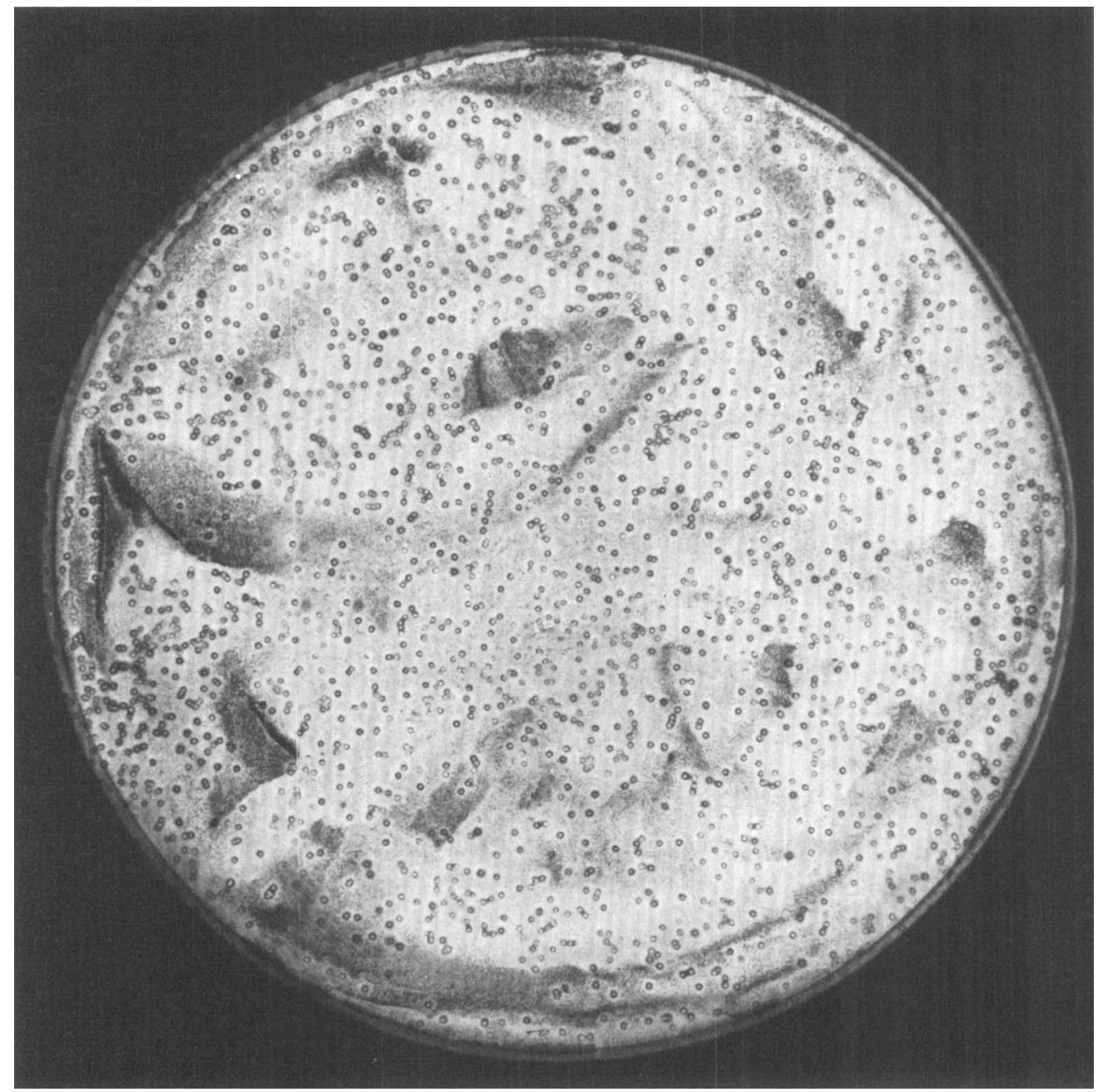

Fig. I. Result of plating the products of a cross of prototrophic strain 1326 with an auxotrophic IF derivative (strain 104) of Streptomyces coelicolor A3(2) on minimal medium with an excess of strain 1326. Only prototrophic growth is seen. Numerous colonies of 1326 converted to IF in the cross are surrounded by zones in which aerial mycelium production by the background unconverted I326 strain has been inhibited.

platings, from the mixed culture alone, would serve to determine the total yield of prototrophic plating units from the mixed culture. This frequency could be related to the frequency, if any, of inhibiting colonies on the second series of plates.

Apparent transfer of SCP I was obtained with one out of the nine UF-like streptomycetes, strain I326. A photograph of a plate revealing IF conversion of this strain is in Fig. I. From the data in Table 2, the frequency of IF amongst spores of this strain derived from mixed cultures with strain 104 was in the region of 0.6 to $3 \%$.

In addition to tests with the nine strains, mixed cultures were also made between strain I04 and six further Streptomyces albus strains kindly supplied by Dr J. Lacey. These strains, numbers $1770-1772$ and $1774-1776$, failed to grow well on MM but did so when $0.5 \%$ 
Table 2. Transfer of plasmid SCP I from A3(2) to 1326

Strain I 326 was crossed with strain I04, a his I uraA I strA I IF derivative of A3(2), and the products of the cross were plated on MM either alone, to give the colony counts in the first column, or mixed with an excess of 1326 , to give the counts of inhibiting colonies in the second column.

$\begin{array}{ccc}\text { Prototrophs on MM } & \begin{array}{c}\text { Inhibiting colonies on } \\ \text { background of } 1326\end{array} & \begin{array}{c}\text { Conversion of } \\ 1326 \text { to } \mathrm{IF} \\ (\%)\end{array} \\ 3.8 \times 10^{7} & 2.1 \times 10^{5} & 0.6 \\ 2.0 \times 10^{6} & 6.4 \times 10^{4} & 3.2 \\ 7.7 \times 10^{3} & 50 & 0.6\end{array}$

Table 3. Origin of Ur variants from IF derivatives of 1326

\begin{tabular}{|c|c|c|c|c|c|c|}
\hline \multirow{3}{*}{$\begin{array}{l}\text { Strain } \\
1671\end{array}$} & \multirow{4}{*}{$\begin{array}{l}\text { Treatment } \\
\text { Control } \\
\text { u.v. }\end{array}$} & \multirow{2}{*}{$\begin{array}{c}\text { Survival } \\
(\%)\end{array}$} & \multicolumn{2}{|c|}{$\begin{array}{l}\text { No. of colonies } \\
\text { examined }\end{array}$} & \multicolumn{2}{|c|}{ UF $(\%)$} \\
\hline & & & Total & UF & Total & Induced* \\
\hline & & 100 & 514 & 4 & 0.8 & - \\
\hline & & 3 & I 577 & 21 & $1 \cdot 3$ & 0.5 \\
\hline \multirow[t]{2}{*}{1672} & Control & 100 & 1396 & 12 & 0.9 & $\bar{x}$ \\
\hline & u.v. & 0.8 & 1190 & 30 & $2 \cdot 5$ & $I \cdot 6$ \\
\hline \multirow[t]{2}{*}{$1671^{\circ}$} & Control & 100 & 929 & 3 & 0.3 & - \\
\hline & u.v. & 4 & 660 & 8 & $1 \cdot 2$ & 0.9 \\
\hline
\end{tabular}

vitamin-free Casaminoacids (Difco) was added. The unsatisfied requirement of uracil by strain 104 prevented its growth on the plating media. No conversion of these $S$. albus strains to IF was detected.

IF derivatives of strain $\mathrm{I} 326$ were isolated by picking the inhibiting colonies on plates of the kind shown in Fig. I with a fine wire and streaking on MM. After two or three streakings, pure IF cultures were obtained, as determined by replication of the plates to lawns of 1326 or a UF derivative of $\mathrm{A}_{3}(2)$.

Stability of IF derivatives of strain 1326

IF strains of Streptomyces coelicolor A3(2) lose the plasmid with a low spontaneous frequency (about 0.03 to $0.3 \%$ ), which is increased to I to $2 \%$ by irradiation with u.v. or X-rays (Vivian \& Hopwood, 1970). Table 3 shows the results of similar stability tests on two separately made If derivatives of 1326 , strains $I 67 I$ and 1672 . The spontaneous rate of loss of SCP I by these strains was very slightly higher than that recorded for two IF derivatives of A3 (2). As in the A3(2) strains, u.v. increased the rate of loss of the plasmid by $1 F$ derivatives of I326, to approximately the same extent.

Transfer of SCP I between derivatives of 1326

A series of auxotrophs of $\mathrm{I} 326$ was isolated after mutagenesis by near u.v. in the presence of 8-methoxypsoralen (Townsend, Wright \& Hopwood, 1971). A spontaneous streptomycinresistant mutant of one of the auxotrophs (I66I cys-I) was selected and a mixed culture of the resulting cys-I str-I strain 1707 was made with strain $167 \mathrm{I}$, a prototrophic IF derivative of strain 1326 . After 3 days of incubation, spores from the mixed culture were plated on MM 
Table 4. Frequencies of recombination in crosses of auxotrophic mutants of strain $\mathbf{1} 326$

\begin{tabular}{|c|c|}
\hline \multicolumn{2}{|c|}{ UF parent I } \\
\hline Genotype & Number* \\
\hline $\arg -9$ & $7.8 \times 10^{7}$ \\
\hline $\arg -9$ & $2.9 \times 10^{7}$ \\
\hline $\arg -9$ & $7 \cdot 3 \times 10^{6}$ \\
\hline$h i s-I$ & $2.0 \times 10^{7}$ \\
\hline his-I & $4.0 \times 10^{7}$ \\
\hline \multicolumn{2}{|c|}{ IF parent I } \\
\hline Genotype & Number* \\
\hline $\arg -9$ & $3.0 \times 10^{7}$ \\
\hline his-I & $3.1 \times 10^{7}$ \\
\hline his-I & $4.7 \times 10^{7}$ \\
\hline$c y s-3$ & $1 \cdot 0 \times 10^{8}$ \\
\hline
\end{tabular}

$\begin{array}{cc}\text { Genotype } & \text { Number* } \\ \text { cys-3 } & 9.5 \times 10^{6} \\ \text { his-I } & 3.4 \times 10^{7} \\ \text { his-I } & 3.3 \times 10^{7} \\ \text { cys-3 } & 2.0 \times 10^{6} \\ \text { cys-3 } & 4.0 \times 10^{7}\end{array}$

Prototrophs $/ 10^{6}$
spores of minority
parent
42
10
4
35
25

\begin{tabular}{cc}
\multicolumn{2}{c}{ UF parent 2} \\
Genotype & Number* \\
his-I & $8.7 \times 10^{7}$ \\
arg-9 & $1.1 \times 10^{7}$ \\
cys-3 & $6.7 \times 10^{7}$ \\
his-I & $4.6 \times 10^{7}$
\end{tabular}
Controls
$\arg -9$
his-I
cys-3

* Per ml of suspension from the cross.

$$
\begin{aligned}
& 7 \\
& 24 \\
& 5 \\
& 14 \\
& \\
&<0.03 \\
&<0.8 \\
&<0.8
\end{aligned}
$$

supplemented with cystine and streptomycin. Three hundred of the resulting colonies were replicated to lawns of $\mathrm{I}_{326}$ on $\mathrm{CM}$ to test for the presence of SCP I in the colonies and to MM and MM plus cystine to verify that the colonies still had the cystine requirement of the 1707 parent, and thus to exclude the possibility of mutation of 1671 to streptomycin resistance. Every one of the colonies tested was of phenotype $\mathrm{Cys}^{-} \mathrm{Str}^{\mathrm{R}} \mathrm{IF}$, indicating a very high rate of transfer of SCP I from an IF to a UF derivative of 1326 ; this rate is the same as that between derivatives of $\mathrm{A} 3(2)$.

\section{Lack of transfer of SCP I from IF derivatives of 1326 back to $\mathrm{A3}(2)$}

Crosses between auxotrophic IF derivatives of I 326 and UF derivatives of A3(2) have so far failed to reveal any transfer of SCP I from 1326 back to $\mathrm{A}_{3}(2)$. When the crosses were studied by the confluent plating method (see Fig. I), no inhibition of the background UF population was seen. When 1000 colonies with the markers of the $\mathrm{A} 3(2)$ parent from the crosses were picked and tested individually, all were found to be UF.

\section{Recombination in strain 1326}

The data in the top part of Table 4 show that recombination occurs in strain 1326 . The frequency of prototroph production in these crosses between pairs of auxotrophs varied between about $4 \times 10^{-5}$ and $4 \times 10^{-6}$ with respect to the minority parent; these frequencies are within the range found in UF $\times$ UF crosses in strain A3(2) (Hopwood et al. 1973). The frequency range was not changed when one of the parents in the cross was converted to IF by SCP I from strain A3(2) (bottom part of Table 4).

\section{Recombination between strains $\mathrm{A} 3(2)$ and $\mathrm{I} 326$}

In Table 5 are the results of crossing derivatives of $\mathrm{A} 3$ (2) carrying the marker phe AI, of each of the three fertility types, UF, IF and NF, with auxotrophs of strain 1326 . The frequency 
Table 5. Frequencies of prototrophs in crosses of auxotrophic derivatives of strains $\mathrm{A} 3(2)$ and $\mathrm{I} 326$

$\begin{array}{cc}\overbrace{\text { Fertility type }}^{\text {A3(2) parent }}(\text { pheAI }) \\ \text { UF } & 5.5 \times 10^{6} \\ \text { UF } & 1.0 \times 10^{7} \\ \text { IF } & 7.4 \times 10^{7} \\ \text { IF } & 8.8 \times 10^{6} \\ \text { NF } & 3.4 \times 10^{6} \\ \text { NF } & 3.3 \times 10^{6} \\ \text { NF } & 8.2 \times 10^{6} \\ \text { NF } & 6.9 \times 10^{6}\end{array}$

\begin{tabular}{|c|c|}
\hline \multicolumn{2}{|c|}{ I 326 parent (UF) } \\
\hline Genotype & Number* \\
\hline$h i s-I$ & $4.6 \times 10^{6}$ \\
\hline$c y s-3$ & $5.5 \times 10^{7}$ \\
\hline his-I & $5.9 \times 10^{6}$ \\
\hline$c y s-3$ & $6.0 \times 10^{7}$ \\
\hline his-I & $1.2 \times 10^{7}$ \\
\hline his-I & $7.5 \times 10^{6}$ \\
\hline cys -3 & $2.2 \times 10^{8}$ \\
\hline$c y s-3$ & $1.3 \times 10^{8}$ \\
\hline
\end{tabular}

Prototrophs $/ 10^{6}$ spores of $\mathrm{A3}(2)$ parent

$<0.2$

$<0.5$

O. I

I

65

33

57

I 26

* Per $\mathrm{ml}$ of suspension from the cross.

Table 6. Relative plating efficiencies of lysates of a clear-plaque mutant of phage VP5 on UF and IF derivatives of $\mathrm{A} 3(2)$ and $\mathrm{I}_{3} 26$

Lysate prepared

on strain

Relative plaque counts of lysates plated on*

$\begin{array}{lllll}\text { UF A3(2) } & 1 \cdot 0 & 0.76 & 0.74 & 0.15 \\ \text { IF A3(2) } & 1 \cdot 0 & 0.80 & 0.58 & 0.25 \\ \text { UF I326 } & 1 \cdot 0 & 0.85 & 0.61 & 0.15 \\ \text { IF I326 } & 1 \cdot 0 & 0.46 & 0.62 & 0.10\end{array}$

* The plaque counts on UF $\mathrm{A} 3(2)$ are set at $\mathrm{I} \cdot 0$. The figures represent the average values from two experiments.

of prototroph production in crosses involving UF and IF derivatives of A3(2) was very low, and probably not significantly above the levels of reversion of the markers (see bottom of Table 4 ). On the other hand, the frequency of recombination in crosses involving the NF strains was much higher, within the range $\mathrm{I} \times 10^{-4}$ to $3 \times 10^{-5}$.

Lack of restriction between strains $\mathrm{A} 3(2)$ and $\mathrm{I} 326$

To test the possibility that low frequencies of plasmid and gene transfer between derivatives of strains $\mathrm{A} 3(2)$ and 1326 might reflect the operation of a restriction-modification system (Boyer, I97I), an experiment was performed to determine the relative efficiency of plating of a bacteriophage lysate that had been prepared on each of four strains, UF and IF derivatives of $\mathrm{A}_{3}(2)$ and 1326 , when assayed on each strain in turn. Of the two best-studied phages isolated in this laboratory, the virulent phage VP I I (Dowding, I973) was found not to attack strain 1326 . Therefore the temperate phage VP 5 was chosen (Dowding \& Hopwood, I973), a clear-plaque mutant being used for the experiments.

The results (Table 6) showed a difference by a factor of 6 in average counts on the four hosts, but this was unrelated to the host on which the phage had been prepared. It probably reflected differences in the vigour of sporulation of the strains, which in turn influenced the proportion of spores in the host suspensions, a factor known to affect the plating efficiency of actinophages (Dowding, 1973). Thus no system capable of restricting VP 5 DNA was detected, in strains with or without SCP I. 


\section{DISCUSSION}

Plasmid transfer in Gram-negative eubacteria has been shown to occur by conjugation between strains belonging to diverse genera, presumed, from the evidence of DNA base composition as well as from general taxonomic considerations, not to be closely related: Escherichia, Salmonella, Shigella, Pasteurella, Proteus, Erwinia, Serratia, Pseudomonas, Rhizobium, Agrobacterium and Klebsiella (Baron, Gemski, Johnson \& Wohlhieter, I968; Lawton, Morris \& Burrows, 1968; Datta et al. 1971; Chatterjee \& Starr, 1972; Dixon \& Postgate, 1972). In such studies, strains which have received a plasmid have been selected by virtue of the expression of plasmid-borne genes conferring prototrophy or drug resistance lacked by auxotrophic or drug-sensitive recipients.

Although gene transfer in streptomycetes occurs by a mechanism which is referred to as conjugation because it can result in the transfer of large segments of the genome of a donor to a recipient strain, we do not know whether its morphological basis is similar to that in Gram-negative eubacteria. Since there are no other known conjugation systems amongst Gram-positive bacteria, there are no closely analogous processes with which the streptomycete system might be compared. Thus, a priori, we cannot guess whether plasmid transfer is likely to occur between different streptomycetes, although reports of interspecific recombination (see references in Sermonti, 1969; and Hopwood, 1972) make this a likely possibility. The current absence of selectable plasmid-borne characters is nevertheless a handicap in its experimental verification.

Strain I 326, although sharing a number of characters with strains commonly referred to as Streptomyces coelicolor or $S$. violaceoruber, is distinct from such strains in several ways and, according to Dr N. D. Lomovskaya (personal communication), has been referred to as S. lividans by Krasilnikov (1965). The present paper has shown that, making use of a visual technique of limited selective power, plasmid transfer to this strain can be demonstrated. The observed frequency of transfer of I to $3 \%$ is doubtless an overestimate since, owing to the long time-span of the crosses and the very efficient transfer of the plasmid within a strain, secondary intrastrain transfer from the first recipients presumably occurs. Moreover, since the IF product prevents aerial mycelium production, and therefore sporulation, by UF strains (Vivian, I 97 I ), there will an enrichment for IF amongst the spore progeny of the cross. Once in the new strain, the stability of the plasmid, spontaneously and after u.v. irradiation, was found to be essentially the same as in its earlier host. However, transfer back to the original host has not been demonstrated. This is probably not due to restriction of foreign DNA, unless by a specific system undetectable by the phage test adopted.

Within the new host, the plasmid does not have an easily detected effect on recombination. In view of the difficulty of measuring in a meaningful way low frequencies of gene transfer in streptomycetes (observed frequencies depend very much on the vigour of asexual reproduction of different pairs of strains: Hopwood et al. 1973), a small average effect of SCP I on gene transfer in strain I 326 cannot be excluded. Nevertheless it is likely that SCP I interacts with the chromosome of strain 1326 at a lower frequency than in strain A3(2). IF derivatives of $\mathrm{A} 3$ (2) have a higher frequency of gene transfer to UF recipients than do UF derivatives (Hopwood et al. 1973), at least some of which is due to the presence of recognizable donor clones, in which segments of chromosome may be associated with SCP I (Vivian \& Hopwood, 1973), within the IF population. Even the normal 'wild-type' SCP I may already share certain base sequences with the chromosome of $\mathrm{A3}_{3}(2)$ that allow it to interact comparatively readily with the chromosome. An imperfect homology between the chromosomes 
of $A 3(2)$ and 1326 is suggested by the low frequency of recombinant production between the two strains, even when an NF derivative of $\mathrm{A} 3(2)$ was involved.

Apart from its relevance to comparative studies of bacterial genetics, perhaps the most interesting aspect of the present study is in connection with the possibility of gene transfer between diverse streptomycetes in industrial strain-improvement programmes. Once specific chromosomal genes can be transferred to a plasmid in its original host, introduction of the modified plasmid into a second host, perhaps not closely related to the first, should lead to expression of the foreign genes, even without the necessity for their integration into the chromosome of the recipient, an event that may be very unlikely owing to poor basesequence homology (Hopwood, 1972).

\section{REFERENCES}

Baron, L. S., Gemski, P., Johnson, E. M. \& Wohlheter, I. A. (1968). Intergeneric tacterial mating. Bacteriological Reviews 32, 362-369.

BOYER, H. W. ( I97I). DNA restriction and modification mechanisms in bacteria. Annual Reviews of Microbiology' 25, $153-176$.

Chatterjee, A. K. \& Starr, M. P. (1972). Transfer among Erwinia spp. and other enterobacteria of antibiotic resistance carried on $\mathrm{R}$ factors. Journal of Bacteriology II2, 576-584.

Datta, N.. Hedges, R. W., Shaw, E. J., Sykes, R. B. \& Richmond, M. H. (1971). Properties of an R factos from Pseudomonas aeruginosa. Journal of Bacteriology ro8, $1244^{-1249 .}$

Dixon, R. A. \& Postgate, J. R. (1972). Genetic transfer of nitrogen fixation from Klebsiella pheumoniae to Escherichia coli. Nature, London 237, 102-103.

Dowding. J. E. (1973). A bacteriophage virulent for Streptomyces coelicolor A3(2). Journal of General Microbiolog. $75,163-176$

Dowding, J. E. \& Hopwood, D. A. ( 1973). Temperate bacteriophages for Streptomyces coelicolor A3(2) isolated from soil. Joumal of General Microbiology (in the press).

Harold, R. J. \& Hopwood, D. A. (1970). Ultraviolent sensitive mutants of Streptomyces coelicolor. 1. Phenoty pic characterisation. Mutation Research 1o, 427-438.

Hopwood, D. A. (1967). Genetic analysis and genome structure in Streptomyces coelicolor. Bacteriological Reviews 3I, 373-403.

Hopwood, D. A. (1972). Genetics of the actinomycetales. In Actinomycetales: Characteristics and Practical Importance, pp. 13I-153. Edited by G. Sykes and F. A. Skinner. London: Academic Press.

Hopwood, D. A., Chater, K. F., Dowding, J. E. \& Vivian, A. (1973). Advances in Streptomyces coelicolor genetics. Bacteriological Review's (in the press).

Hopwood, D. A., Harold, R. J., Vivian, A. \& Ferguson, H. M. (1969). A new kind of fertility variant in Streptomyces coelicolor. Genetics 62, 46I-477.

Krasilnikov, N. A. (1965). Biology of Separate Groups of Actinomycetes. Moscow: Nauka.

KutZner, H. J. \& Waksman, S. A. (I959). Streptomyces coelicolor Müller and Streptomyces violaceoruber Waksman and Curtis, two distinctly different organisms. Journal of Bacteriology $78,528-538$.

Lawton, W. D., Morris, B. C. \& Burrows, T. W. (1968). Gene transfer in strains of Pasteurella pseudotuberculosis. Journal of General Microbiology' 52, 25-34.

Lomovskaya, N. D., Mkrtumian, N. M., Gostimskaya, N. L. \& Danilenko, V. N. (1972). Characterization of temperate actinophage $\emptyset_{31}$ isolated from Streptomyces coelicolor $\mathrm{A}_{3}(2)$. Journal of Virology $\mathbf{9}$. $258-262$.

Sermonti, G. (1969). Genetics of Antibiotic-producing Microorganism.s. London: Wiley-Interscience.

Sermonti, G. \& CASciano, S. (1963). Sexual polarity in Streptomyces coelicolor. Journal of General Microbiology' 33, 293-30r.

Townsend. M. E., Wright, H. M. \& Hopwood, D. A. (197I). Efficient mutagenesis by near ultraviolet light in the presence of 8-methoxypsoralen ir Streptomyces. Joutnal of Applied Bacteriology 34, 799-80I.

Vivian, A. (1971). Genetic control of fertility in Streptomyces coelicolor A3(2): plasmid involvement in the interconversion of UF and IF strains. Journal of General Microbiology 69, 353-364.

Vivian, A. \& Hopwood, D. A. (1970). Genetic control of fertility in Streptomyces coelicolor A3(2): the If fertility type. Journal of General Microbiology 64, $101-117$.

Vivian, A. \& Hopwood, D. A. (1973). Genetic control of fertility in Streptomyces coelicolor A3(2): new kinds of donor strains. Journal of General Microbiology 76, 147-162. 